\title{
Pattern of Growth and Development of the Strawberry Cultivars Elsanta, Bolero, and Everest
}

\author{
M.E. Pérez de Camacaro, ${ }^{1}$ G.J. Camacaro, ${ }^{2}$ P. Hadley, N.H. Battey, and J.G. Carew ${ }^{3}$ \\ Soft Fruit Technology Group, Department of Horticulture and Landscape, The University of Reading, \\ Whiteknights, RG6 6AS, U.K.
}

\begin{abstract}
AdDitional INDEX wORDs. Fragaria $\times$ ananassa, radiation use efficiency, harvest index
Abstract. The differences in growth and yield in the Junebearing strawberry (Fragaria $\times$ ananassa Duch.) 'Elsanta' and the everbearing 'Bolero' and 'Everest' were evaluated under field conditions. The seasonal patterns of radiation use efficiency and assimilate partitioning were also studied. Growth, development and yield showed considerable differences among cultivars. 'Elsanta' showed the highest and 'Bolero' and 'Everest' the lowest values for almost all the vegetative parameters (leaf area, leaf dry weight, runner number). 'Elsanta' produced large leaves and few crowns per plant in contrast to the everbearing cultivars which had more but smaller leaves and a larger number of crowns per plant. The production of flowers by 'Elsanta' was concentrated in June with fruit production following in July. 'Bolero' and 'Everest' produced more than one flush of flowers during the season and fruited until October. As a result, yields of 'Bolero' and 'Everest' were greater than 'Elsanta'. The higher yields of 'Bolero' and 'Everest' also reflected the greater number of crowns produced by these cultivars. The maximum intercepted and absorbed photosynthetically active radiation $(P A R)$ occurred between July and August when the three cultivars showed the greatest increase in vegetative growth. Harvest index clearly differed among cultivars and this was related to the duration of cropping. The greatest harvest indexes were found for 'Bolero' and 'Everest'.
\end{abstract}

Most of the strawberry (Fragaria $\times$ ananassa Duch.) production in the United Kingdom takes place in the open field and the greatest proportion of fruit is produced by Junebearing cultivars during June and July. Cultivars such as Elsanta are used in early production (Beech and Simpson, 1989; Righelato and Traill, 1995). 'Elsanta' has established itself as the major cultivar in Northern Europe and produces a high yield of high quality fruit that is preferred by the supermarkets and by the industry (Day, 1988; Righelato and Traill, 1995).

Growers extend production of strawberries outside the main season using everbearing and day-neutral cultivars such as 'Bolero' and 'Everest', which produce a later crop (August to September) in unprotected field conditions (Simpson et al., 1997). Everbearers are defined as plants which fruit two or more times per season, the summer flowering period being governed by long photoperiods. Day-neutrals are defined as plants that do not enter dormancy in the fall, flowering being continuous until temperatures become too cold (Hancock et al., 1996). There is considerable confusion in the literature and the horticultural community regarding this distinction but in this paper, we have described 'Everest' and 'Bolero' as everbearers according to U.K. nomenclature.

It has been demonstrated that Junebearing, everbearing and day-neutral cultivars show very different patterns of vegetative growth, flowering and fruiting. Durner et al. (1984) suggested that each cultivar has particular genetically controlled thermal requirements for differentiation and growth. Nicoll and Galletta

Received for publication 14 Mar. 2002. Accepted for publication 21 Aug. 2002 We acknowledge financial support from Universidad Centroccidental Lisandro Alvarado and Consejo Nacional de Investigaciones Desarrollo Científicas y Tecnológicas in Venezuela and The University of Reading Soft Fruit Technology Group. We also thank John Handford (Farm Advisory Services Ltd., Faversham, U.K.) and Mike Dennett (The University of Reading) for their advice on the work. ${ }^{1}$ Present address: Universidad Centroccidental Lisandro Alvarado (U.C.L.ATorres), Av. Francisco de Miranda, Carora, Estado Lara, Venezuela. mperezdecamacaro@hotmail.com.

${ }^{2}$ Department of Agriculture, Earley Gate, The University of Reading, Whiteknights Road, P.O. Box 236, Reading, RG6 6AR, U.K.

${ }^{3}$ Corresponding author.
(1987) reported that plant architecture and development patterns were as variable among everbearing clones as among Junebearers. They found that everbearers were usually smaller plants with more crowns than Junebearers. The growth pattern and yield of the strawberry is ultimately dependent upon the quantity of dry matter formed and its distribution to the various plant organs. The amount of dry matter produced by a crop is very important, because $90 \%$ to $95 \%$ of a plant's dry weight is derived from photosynthesis (Biscoe and Gallagher, 1978) and the understanding of the use of assimilates within a plant is vital to the improvement of crop yield. Strawberries are known to be a very strong sink for photoassimilates, accumulating $40 \%$ to $50 \%$ of the plant's total dry weight (Nishizawa, 1994; Olsen et al., 1985).

Most research so far has been conducted on 'Elsanta' and several aspects of growth and yield have been studied in this cultivar (Daugaard, 1999; Le Mière et al., 1996, 1998; Tehranifar et al., 1998). There have, however, been few studies undertaken using everbearing cultivars and none to determine their light use and dry matter partitioning patterns. In the work described here the differences in vegetative growth, reproductive development, and cropping in 'Elsanta', 'Bolero', and 'Everest' were investigated. The seasonal pattern of growth in these cultivars, and its relation to radiation use efficiency and partitioning patterns, were investigated.

\section{Materials and Methods}

Cold stored $\mathrm{A}^{+}$graded plants (crown diameter $\geq 15 \mathrm{~mm}$ ) of 'Elsanta' and 'Bolero' were provided by Darby Brothers Farms Ltd., Kings Lynn, U.K. 'Everest' was provided by E. Vinson and Sons Ltd., Faversham, U.K. The research was conducted in the experimental grounds of the School of Plant Sciences at The University of Reading, U.K. The plants were planted out on 8 May 1999 in an area of $74.75 \mathrm{~m}^{2}$ at a spacing of $25 \mathrm{~cm}$ between plants in a square planting system. The experiment was arranged as a completely randomized block design with three treatments ('Elsanta', 'Bolero', and 'Everest') and two blocks per cultivar, giving a total of six blocks in the experiment. Each block 
consisted of a total of 136 plants. In each block four rows of plants were used for measurements and two outer rows were guard rows. From each block, a sample of eight plants was destructively harvested monthly for 6 months. At planting and then each month between June and November 1999 inclusive, the following were measured: leaf number, leaf area, leaf dry weight, and crown number.

In addition, 10 plants remained in place in each block for the duration of the experiment. The following parameters were recorded weekly from these plants: number of open flowers, total number of developing and expanded leaves, and number of runners or stolons which were removed after counting. Fruit were picked twice weekly from the sample 10 plants throughout the experiment. The fruit were classified as marketable (size $>6 \mathrm{~g}$, shape and color uniform and typical of the cultivar) or nonmarketable (defects of shape, pests, diseases and other damage). Fruit $>6 \mathrm{~g}$ were selected as marketable because this weight equates to fruit $\approx 22 \mathrm{~mm}$ in diameter and so is considered marketable according to E.U. specifications. The fruit number and fresh and dry weight were recorded. Dry weight measurements were made on a 100-g sample of fresh fruit. These measurements were used to calculate total fruit yield after the last harvest. Leaf area was measured using a leaf area meter (Delta-T Devices, Cambridge, U.K.). A sunfleck ceptometer (model SF80; Delta-T Instruments, Cambridge, U.K.) was used to take direct measurements of photosynthetically active radiation $(P A R)$ at various points in the canopy. Light interception was measured at four positions between each row below the canopy. These values were averaged, giving the average light level below the leaf canopies. Likewise, two measurements per block were made above the canopy. Measurements were taken at 7- to 10-d intervals. Radiation use efficiency (RUE) in $\mathrm{g} \cdot \mathrm{MJ}^{-1}$ was calculated as the ratio of total dry matter produced $\left(\mathrm{g} \cdot \mathrm{m}^{-2}\right)$ including root weight to the cumulative absorbed $P A R\left(\mathrm{MJ} \cdot \mathrm{m}^{-2}\right)$ within the same period (Gallagher and Biscoe, 1978). Harvest Index $(\mathrm{HI})$ was calculated as the ratio of fruit dry matter harvested $\left(\mathrm{g} \cdot \mathrm{m}^{-2}\right)$ to total dry matter including roots $\left(\mathrm{g} \cdot \mathrm{m}^{-2}\right)$.

Analysis of variance and means were

Fig. 1. Leaf area (A), accumulated leaf number $(\mathbf{B})$, and leaf dry weight (C) per plant throughout the season. Leaf area and leaf dry weight measurements were made on batches of plants destructively harvested monthly throughout the experiment. Leaf numbers were recorded from 10 plants that remained in situ throughout the experiment. Vertical bars $=$ LSD.

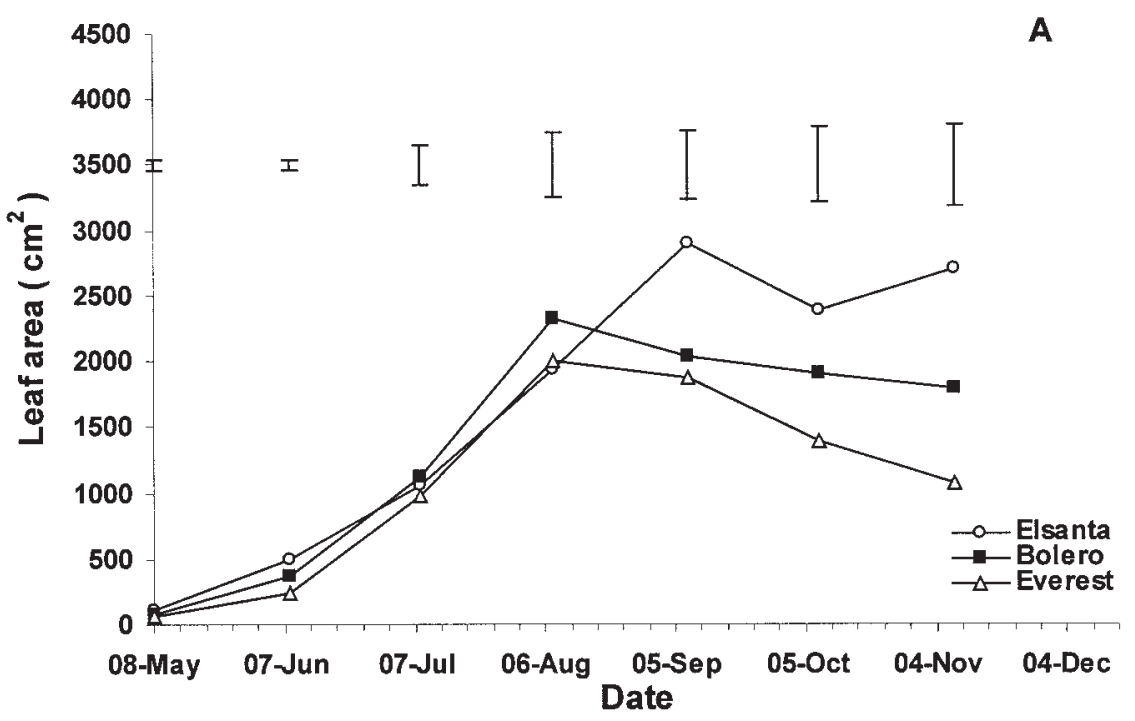

B
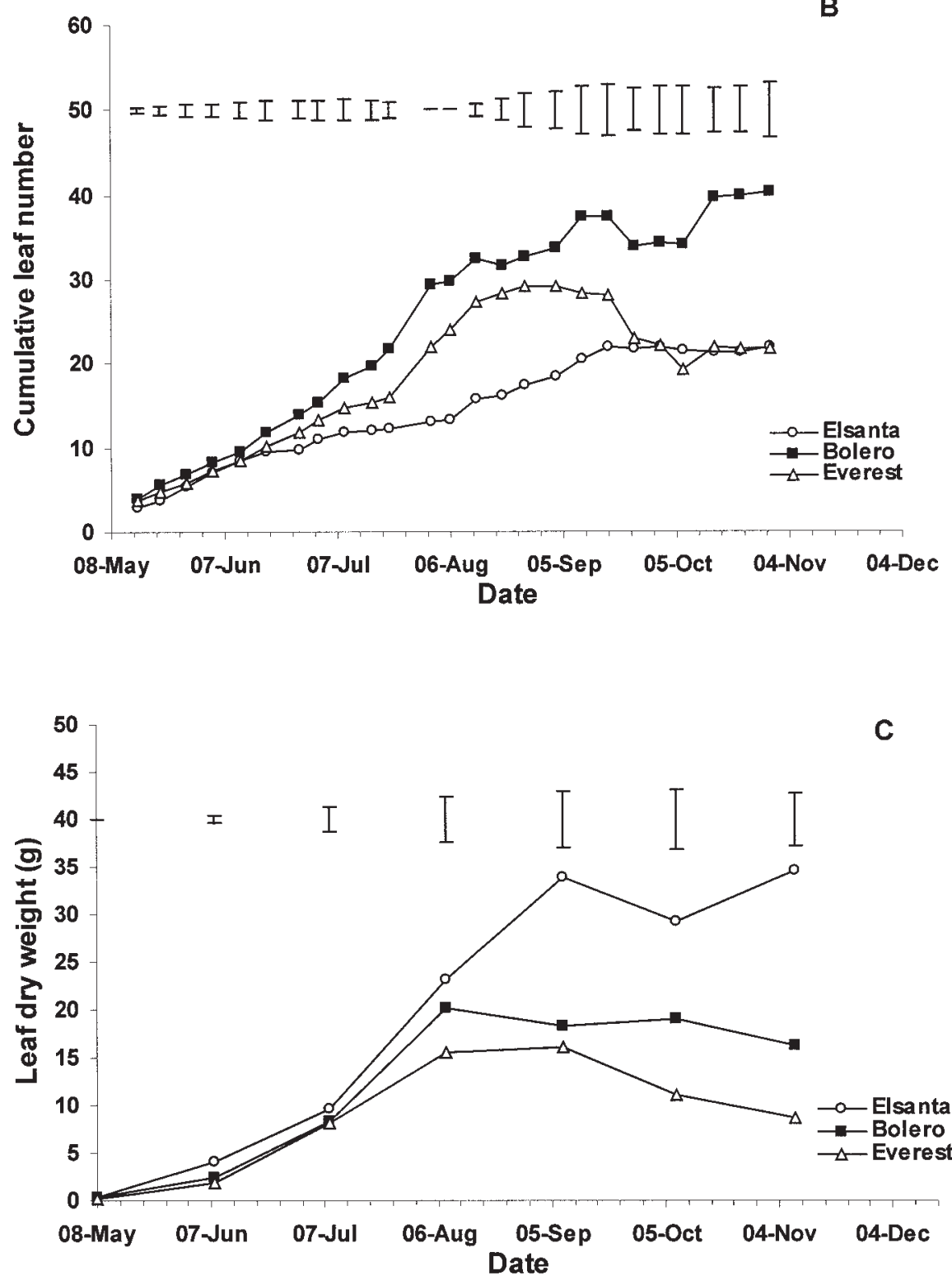
calculated using ANOVA and LSD procedures from the SAS statistical computer program (version 6.08). Standard errors were calculated using Microsoft Excel version 5.0 for Windows 97, which was also used to produce graphs, tables and organize data. Standard errors of harvest index were derived from standard errors of fruit and vegetative dry weights.

\section{Results}

Vegetative GROWTH. Differences in leaf area were statistically significant $(P<0.05)$ between cultivars, except at the second harvest (July) (Fig. 1a). There was a rapid increase in leaf area with time in 'Bolero' and 'Everest' from May to August and until mid-September in 'Elsanta'. Initially and at the end of the experiment 'Elsanta' produced the largest and 'Everest' the smallest leaf area. The pattern of leaf production was similar in all cultivars during May and June but following this, leaf production was greater in 'Bolero' and 'Everest' than in 'Elsanta' (Fig. 1b).

Differences in leaf number among cultivars were significant $(P<0.001)$ during the latter part of the season. 'Bolero' and 'Everest' produced the greatest and 'Elsanta' the least numbers of leaves throughout the experiment. For the three cultivars, similar patterns of increase in leaf dry weight were observed between May and early August (Fig. 1c). However, differences between cultivars in the leaf dry weights of plants towards the end of the experiment were significant $(P<0.05)$. 'Elsanta' had the highest and 'Everest' the lowest values of leaf dry weight during the experiment. However, 'Bolero' and 'Everest' reached maximum leaf dry weight earlier than 'Elsanta'.

Numbers of crowns produced by the cultivars were significantly different $(P<0.001)$ during the latter part of the season (Fig. 2a). 'Bolero' produced more crowns than 'Everest' and 'Elsanta'. The numbers of crowns produced by 'Bolero' and 'Everest' were greater than 'Elsanta' at the end of the experiment. 'Bolero' and 'Everest' showed similar patterns of runner production throughout the experiment (Fig. 2b). The main differences in the pattern of runner production were between 'Elsanta', and 'Bolero' and 'Everest' $(P<0.05)$. The production of runners by all three cultivars started in June but slightly earlier in 'Bolero' than in 'Elsanta' and 'Everest'. 'Elsanta' produced more runners than the other cultivars from mid-July to the end of the experiment.

Flower Production. Flowering started earlier in 'Bolero' and 'Everest' than in 'Elsanta' but, in general, similar patterns of flower emergence were observed for all cultivars during June and early July (Fig.

Fig. 2. Crown (A) and runner number (B) per plant throughout the season. Measurements were taken from 10 plants that remained in situ throughout the experiment. Vertical bars $=$ LSD. 3a). At the end of this period 'Elsanta' stopped producing flowers. Flower production peaked for 'Elsanta' in mid-June (5.6 flowers/ plant/week), for 'Bolero' in early August (16.4 flowers/plant/ week), and for 'Everest' in late August (7.5 flowers/plant/week). From the end of August to mid-October, flower production per plant was greater in 'Everest' than 'Bolero'.

FruIT PRODUCTION AND YIELD. Fruiting began in early July for all three cultivars (Fig. 3b). However, the Junebearing 'Elsanta' only fruited in July and its highest peak of cropping was $\approx 400$ $\mathrm{g} \cdot \mathrm{m}^{-2}$. In 'Bolero' and 'Everest', fruiting extended until October and the highest peak of cropping from each of these was $\approx 600$ $\mathrm{g} \cdot \mathrm{m}^{-2}$, in September. There were significant differences $(P<0.05)$ in total yield per plant and per area among cultivars. The period of fruit production was longer in 'Everest' than in 'Bolero'. Likewise, yield per plant and per area were greater in 'Everest' than 'Bolero' (Fig. 4a and b).

RADIATION ABSORPTION AND RADIATION USE EFFICIENCY. During early canopy formation, between May and July, PAR interception increased rapidly before reaching a maximum in all cultivars ( $90 \%$ to $99 \%$ ). These levels were maintained until the end of the
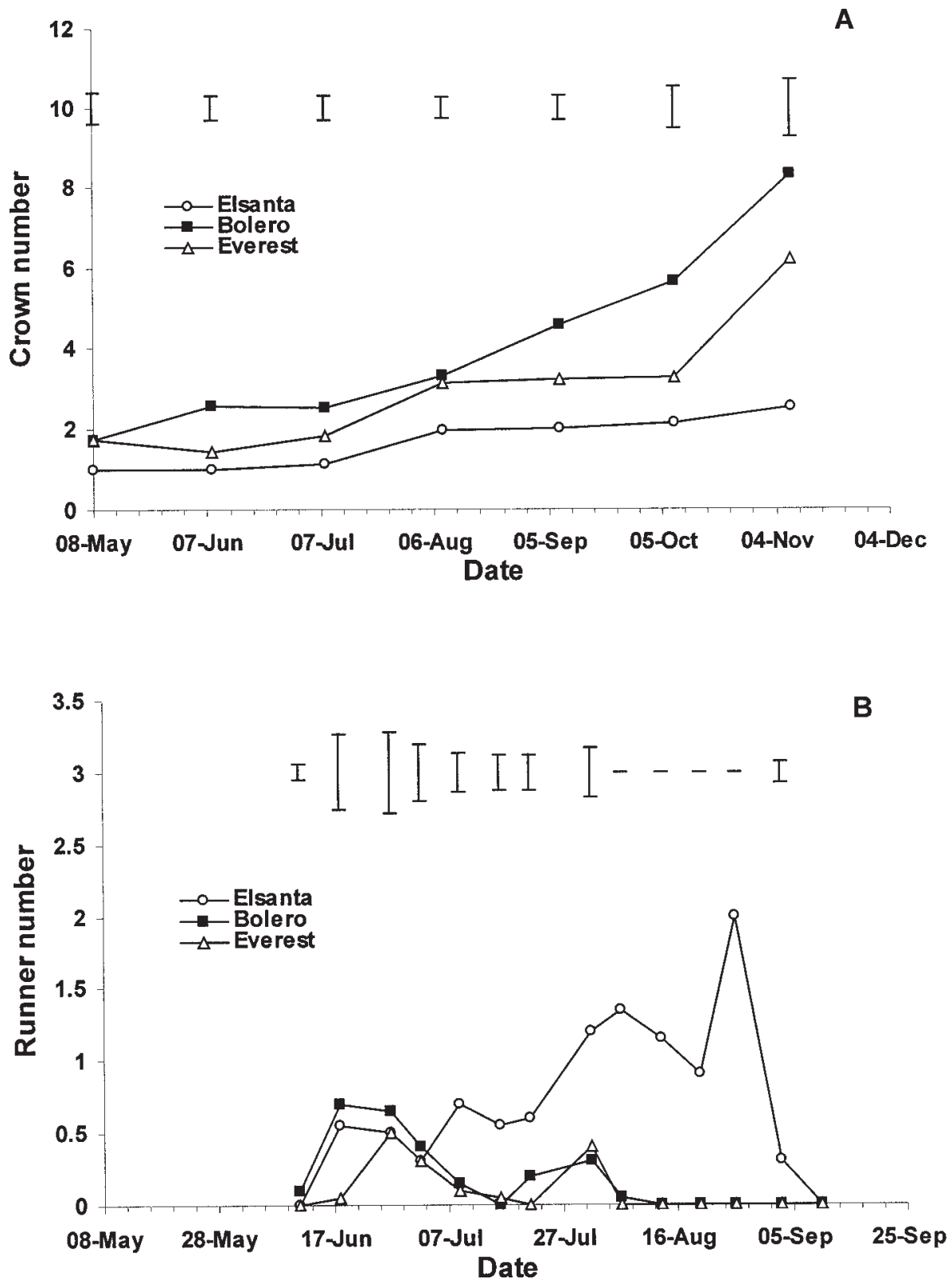

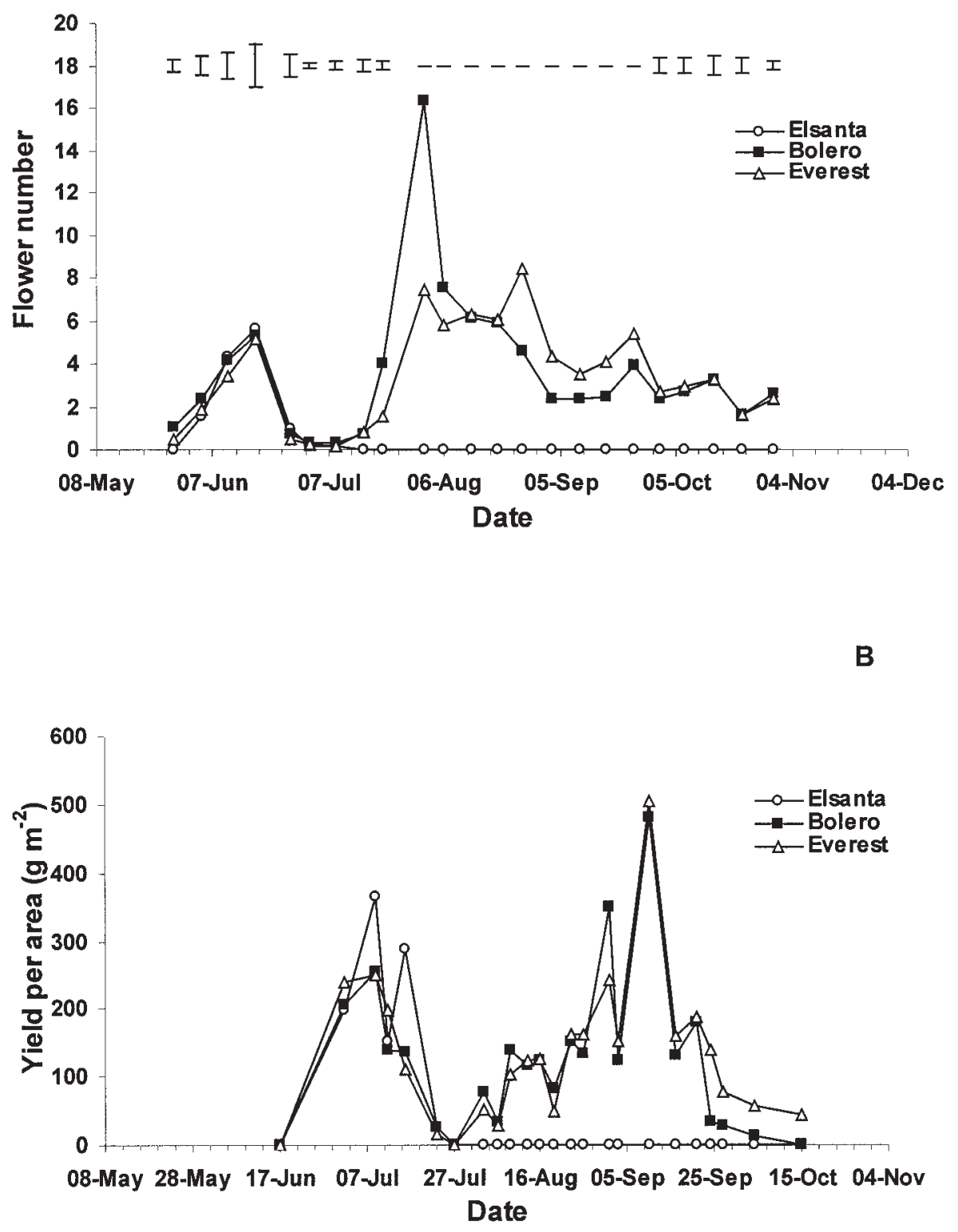

Fig. 3. Pattern of flower production per plant $(\mathbf{A})$ and yield per area $(\mathbf{B})$ throughout the season. Flower number was recorded weekly and included only flowers that had emerged during the preceding week. Fruit number is shown as total number of fruit per plant (marketable and nonmarketable combined).

experiment (Fig. 5a). Similar patterns of increase in the amount of absorbed $P A R$ were observed for each cultivar throughout the season (Fig. 5b). However, during the early stages, the greatest fraction of absorbed PAR was by 'Bolero' and the least by 'Everest'. Radiation use efficiency (RUE) varied among cultivars and between stages of growth (Fig. 6). Before July, RUE was generally less than $1.0 \mathrm{~g} \cdot \mathrm{MJ}^{-1}$. From July to August, the RUE increased, reaching values of $1.47 \mathrm{~g} \cdot \mathrm{MJ}^{-1}$ in 'Elsanta' and 1.36 and $1.23 \mathrm{~g} \cdot \mathrm{MJ}^{-1}$ in 'Bolero' and 'Everest', respectively. Following this the differences in RUE between cultivars were not as great. Average radiation use efficiencies over the growing season were $1.47,1.30$ and $1.18 \mathrm{~g} \cdot \mathrm{MJ}^{-1}$ for 'Elsanta', 'Bolero' and 'Everest', respectively.

HaRVEST INDEX. HI varied among cultivars during the season. 'Everest' had the highest and 'Bolero' the lowest HI values. At the
B

last harvest, $26 \%, 46 \%$, and $59 \%$ of the total dry matter had been partitioned into the fruit in 'Elsanta', 'Bolero' and 'Everest', respectively (Fig. 7). However, it should be noted that for 'Elsanta', HI is only shown for JulyAugust as this was the only period during which the plants fruited.

\section{Discussion}

This study was undertaken to provide a detailed characterization of the seasonal pattern of growth and reproduction in Junebearing 'Elsanta' and everbearing 'Bolero' and 'Everest' strawberry cultivars currently important in Europe.

Vegetative growth in 'Elsanta' (Junebearer) was greater than in 'Bolero' and 'Everest' (everbearers). The main increase in vegetative growth of 'Elsanta' occurred after fruiting, suggesting that reproductive development may antagonize vegetative growth. If this is so, then the continuous flowering or fruiting habit of the everbearing cultivars may constrain vegetative growth. The lack of separation of vegetative and reproductive growth has previously been advanced as an explanation for the smaller plant size of everbearers (Nicoll and Galletta, 1987). Yields were much greater, however, in the everbearing cultivars than in the Junebearer, this effect being determined by the greater number of crowns per plant and by the longer period of production. Yield has been shown previously to be related to the number of parent plants and crowns at fruiting in strawberry (Mason, 1987; Mason and Rath, 1980; Wilson and Dixon, 1988). In addition, yield per plant in 'Elsanta' was low compared to 'Bolero' and 'Everest', but yield per plant in 'Bolero' and 'Everest' as well as yield per area in the three cultivars was comparable with commercially acceptable yields in the United Kingdom (Biddlecombe, 2000; Moore, 1999). However, it is important to remember that plants were grown in conditions different from those found commercially. For example, double row raised bed systems were not used because the sample plants needed to be surrounded by guard plants.

It is also of interest that the two everbearing cultivars performed in a very similar way throughout the season, with minor differences in growth and yield. This is in spite of their very different genetic backgrounds. 'Bolero' is a cross between the day-neutral 'Selva' and the short day breeding line LA988 (Simpson et al., 1997) and 'Everest' resulted from a cross between the day-neutrals 'Evita' and 'Irvine' (Vinson, 1998).

The maximum $P A R$ intercepted and absorbed as well as the maximum RUE occurred in July and August, the period in which all the cultivars showed the greatest vegetative growth. The plants were more efficient at absorbing light due to the increase in leaf number and leaf area (Biscoe and Gallagher, 1978; Monteith, 1977; Russell et al., 1989). Cultivars showed slight differences in 

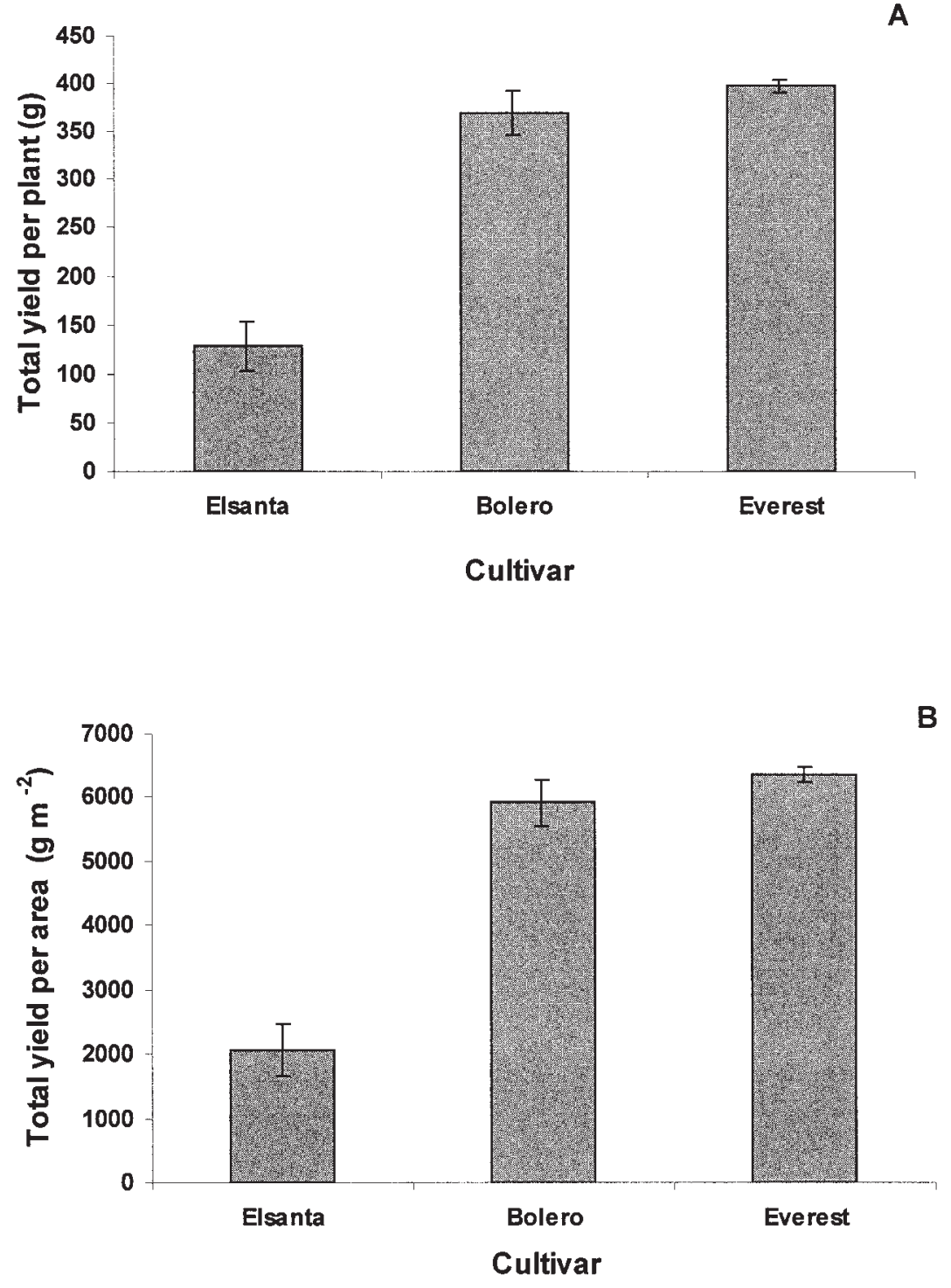

Fig. 4. Total yield per plant (A) and per area (B) throughout the season (marketable and nonmarketable combined). Vertical bars \pm SE.

the amount of absorbed $P A R$ in July and August as a result of differences in leaf area. However, during this period, differences in RUE between cultivars were more important than differences in PAR absorbed. The difference in RUE between cultivars at this time could be due to Elsanta having a greater rate of vegetative growth (principally leaf area) than Bolero and Everest. In addition, flowering and fruiting in 'Bolero' and 'Everest' continued for a greater duration than in 'Elsanta'. This may have reduced growth in these cultivars during this period due to vegetative growth inhibition as a result of the increased assimilate demand by the fruit (Forney and Breen, 1985; Nishizawa, 1994). The values of RUE obtained in this experiment in the three cultivars are comparable to the results found by Wright and Sandrang (1995) in 'Hapil' under full sunlight and close to those values described by Monteith (1977) as typical values for $\mathrm{C}_{3}$ plants. Fruiting over an extended period, however, results in changes in the RUE of each cultivar and so generalization of these data is therefore difficult.

$\mathrm{HI}$ varied between cultivars and the largest values were found in 'Bolero' and 'Everest'. This was because these cultivars 
produced fruit for a greater duration and as a result the plants were able to partition a greater amount of assimilates into the fruit. The results for HI therefore showed clearly the difference in the accumulation of fruit dry weight between 'Elsanta', and 'Bolero' and 'Everest' in relation to the period of production. These differences again could be due to the fruiting effects on dry matter partitioning (Forney and Breen, 1985). It is also known that HIs may vary within genotype and with changes in the environmental conditions as the season progresses (Sinclair and Gardner, 1998).

It becomes clear that both HIs and RUEs change during the season according to cropping pattern. Manipulation of these factors will be critical in the development of optimized production systems in the future. High rates of vegetative growth early in the season to maximize RUE and an extended cropping pattern to maximize HI seem to be important.

\section{Literature Cited}

Beech, M.G. and D.W. Simpson. 1989. Strawberry production in the United Kingdom. Acta Hort. 265:693696.

Biddlecombe, T. 2000. Aids to planning. Proc. FAST Soft Fruit Conf. 2000, Faversham, Kent, U.K. p. 54-63.

Biscoe, P.V. and J.N. Gallagher. 1978. A physiological analysis of cereal yield. I. Production of dry matter. J. Agr. Educ. Assn. 53:34-49.

Daugaard, H. 1999. The effect of flower removal on the yield and vegetative growth of $\mathrm{A}^{+}$frigo plants of strawberry (Fragaria $\times$ ananassa Duch.). Sci. Hort. 82:153157.

Day, D. 1988. Strawberries. Grower Books, Swanley, U.K.

Durner, E.F., J.A. Barden, D.G. Himelrick, and E.B. Poling. 1984. Photoperiod and temperature effects on flower and runner development in day-neutral, Junebearing, and everbearing strawberries. J. Amer. Soc. Hort. Sci. 109:396-400.

Forney, C.F. and P.J. Breen. 1985. Dry matter partitioning and assimilation in fruiting and deblossomed strawberry. J. Amer. Soc. Hort. Sci. 110:181-185.

Gallagher, J.N. and P.V. Biscoe. 1978. Physiological analysis of cereal yield. II. Partitioning of dry matter. J. Agr. Educ. Assn. 53:51-69.

Hancock, J.F., D.H. Scott, and F.J. Lawrence. 1996. Strawberries. In: J. Janick and J.N. Moore (eds.). Fruit breeding. vol. 2. Vine and small fruits. Wiley, New York.

Le Mière, P., P. Hadley, J. Darby, and N.H. Battey. 1996. The effect of temperature and photoperiod on the rate of flower initiation and the onset of dormancy in the strawberry (Fragaria $\times$ ananassa Duch). J. Hort. Sci. 71:361-371.

Le Mière, P., P. Hadley, J. Darby, and N.H. Battey. 1998. The effect of thermal environment, planting date and crown size on

Fig. 6. Radiation use efficiency (RUE, g.MJ'-1) throughout the season. RUE was calculated as the ratio of total dry matter produced $\left(\mathrm{g} \cdot \mathrm{m}^{-2}\right)$, including root weight to the cumulative absorbed photosyn-thetically active radiation $\left(P A R, \mathrm{MJ} \cdot \mathrm{m}^{-2}\right)$ withinthesameperiod(GallagherandBriscoe, 1978).
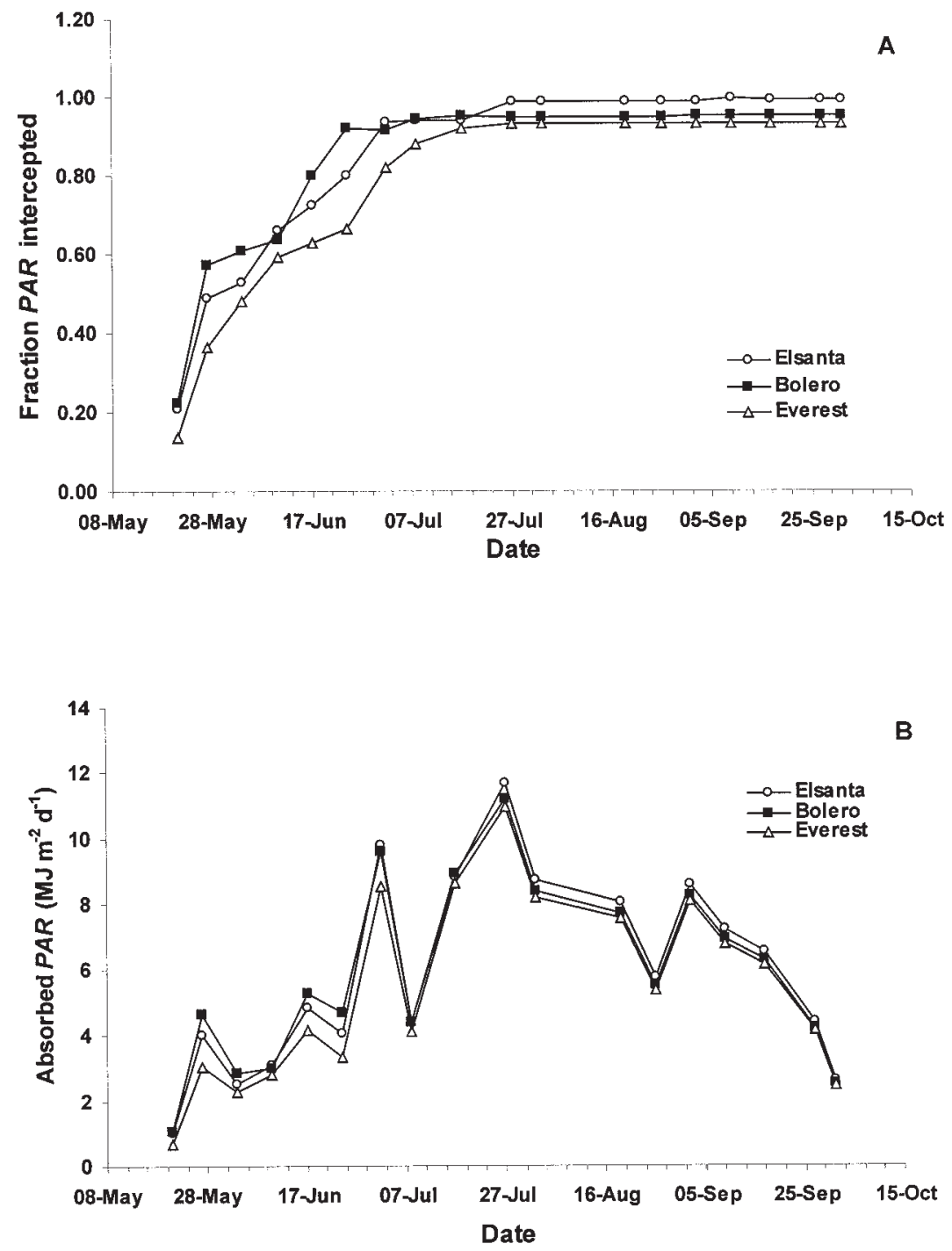

Fig. 5 Fraction of photosynthetically active radiation $(P A R)$ intercepted $(\mathbf{A})$ and absorbed (B) throughout the season. A sunfleck ceptometer was used to take direct measurements of $P A R$ above and below the canopy at 7- to 10-d intervals. The fraction of $P A R$ intercepted was calculated as the ratio of $P A R$ below and above the canopy. The amount of PAR absorbed was defined as the difference in $P A R$ above and below the canopy.

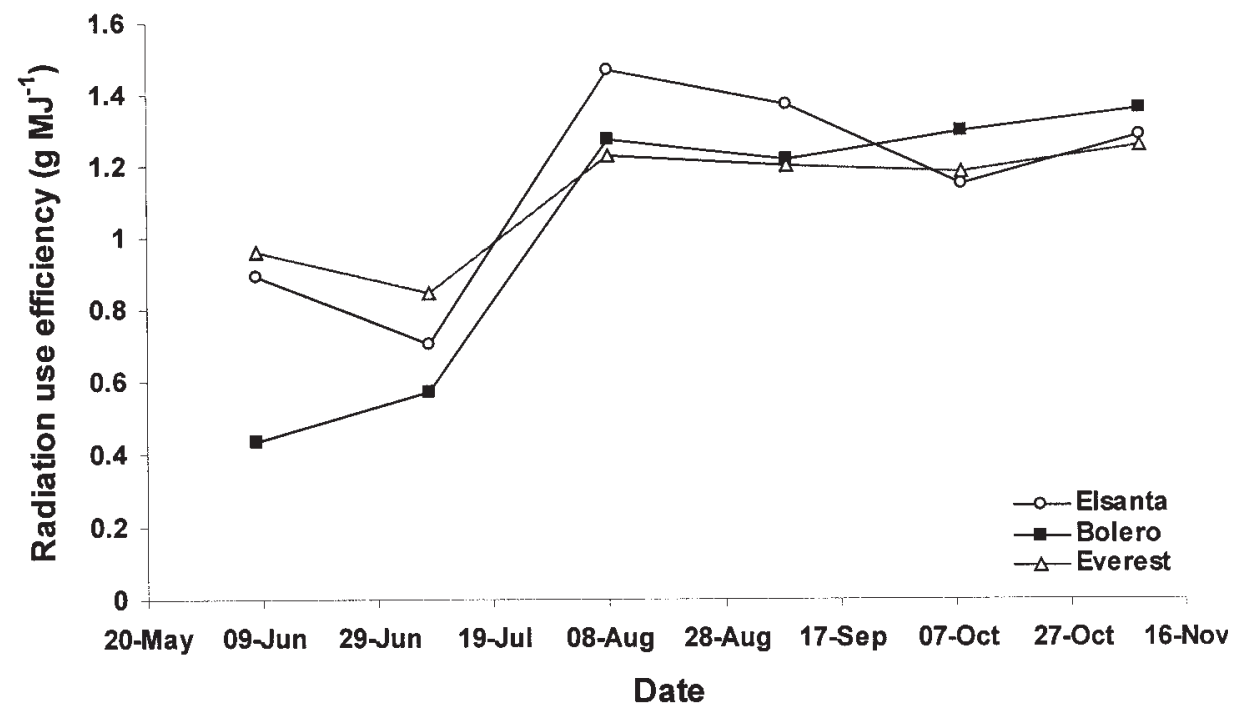




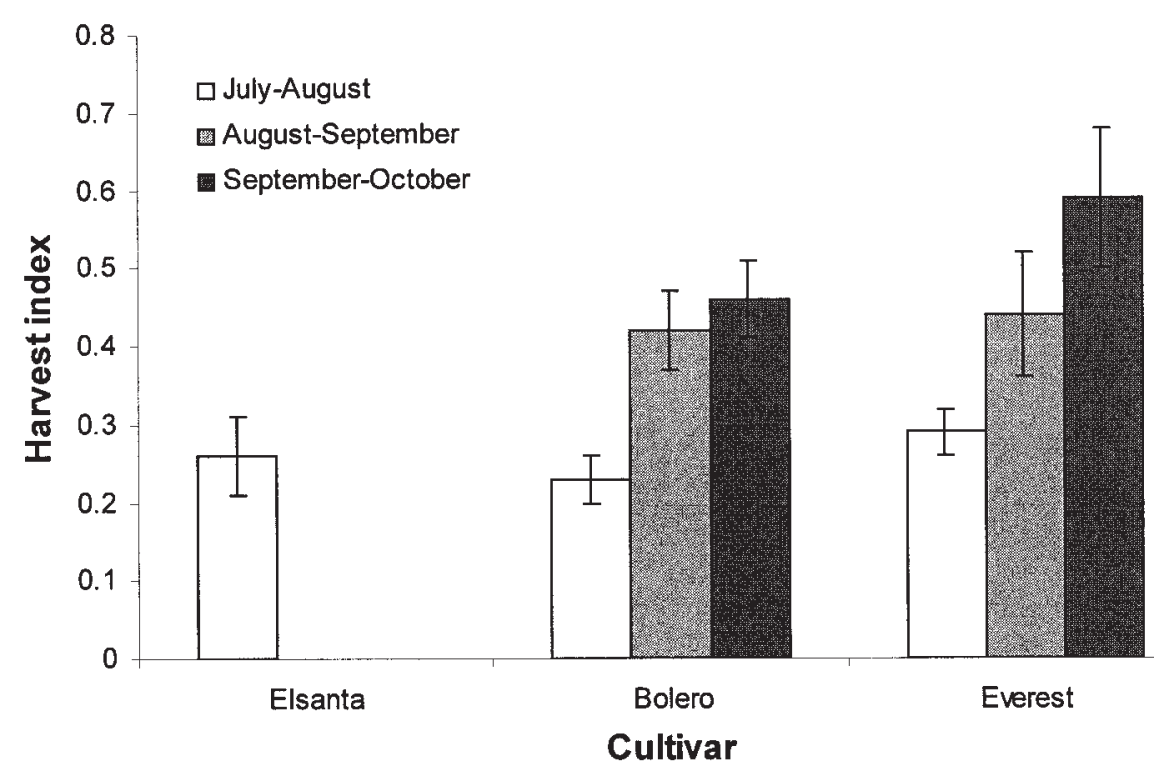

Fig. 7. Harvest index (HI) throughout the season. HI was calculated as the ratio of fruit dry matter $\left(\mathrm{g} \cdot \mathrm{m}^{-2}\right)$ harvested by the dates shown to total dry matter (including roots) at that point. Vertical bars $\pm \mathrm{SE}$.

growth, development and yield of Fragaria ×ananassa Duch. cv. Elsanta. J. Hort. Sci. Biotechnol. 73:786-795.

Mason, D.T., 1987. Effect of initial plant size on the growth and cropping of the strawberry (Fragaria $\times$ ananassa Duch ). Crop Res. 27:31-47.

Mason, D.T. and N. Rath. 1980. The relative importance of some yield components in East of Scotland strawberry plantations. Ann. Appl. Biol. 95:399-408.

Monteith, J.L. 1977. Climate and the efficiency of crop production in Britain. Philosoph. Trans. Roy. Soc. London B. 281:277-294.

Moore, G. 1999. Making the most of Everbearers. Proc. FAST Soft Fruit Conf., Faversham, Kent, U.K. p. 68-75.

Nicoll, M.F. and G.J. Galletta. 1987. Variation in growth and flowering habits of Junebearing and everbearing strawberries. J. Amer. Soc. Hort. Sci. 112:872-880.

Nishizawa, T. 1994. Comparison of carbohydrate partitioning patterns between fruiting and deflorated Junebearing strawberry plants. J. Jpn. Soc. Hort. Sci. 62:795-800.

Olsen, J.F., L.W. Martin, P.J. Pelofske, P.J. Breen, and C.F. Forney. 1985. Functional growth analysis of field grown strawberry. J. Amer. Soc. Hort. Sci. 110:89-93.

Righelato, R.C. and B. Traill. 1995. Strawberries in the U.K. Technology foresight in horticulture. MAFF, London.

Russell, G., B. Marshall, and P.G. Jarvis. 1989. Absorption of radiation by canopies and stand growth, p. 21-40. In: B.M.G. Russell and P.G. Jarvis. (eds.). Plant canopies: Their growth, form and function. vol. 31. Soc. Expt. Biol. Sem. Ser., Cambridge, U.K.

Simpson, D.W., J.A. Bell, and K.J. Graham. 1997. Progress in breeding strawberries for an extended season in the United Kingdom. Acta Hort. 439:133-137.

Sinclair, T.R. and F.P. Gardner. 1998. Principles of ecology in plant production. CAB Intl., Gainesville, Fla.

Tehranifar, A., P. Le Mière, and N.H. Battey. 1998. The effect of lifting date, chilling duration and forcing temperature on vegetative growth and fruit production in the Junebearing strawberry cultivar 'Elsanta'. J. Hort. Sci. Biotechnol. 73:453-460.

Vinson, P. 1998. Everest and Everglade, the story so far. Proc. ADAS/ HRI/EMRA Soft Fruit Conf., Ashford, Kent, U.K. p. 48-52.

Wilson, F.M. and G.R. Dixon. 1988. Strawberry growth and yield related to plant density using matted row husbandry. J. Hort. Sci. 63:221-227.

Wright, C. and A.K. Sandrang. 1995. Efficiency of light utilization in the strawberry (Fragaria ×ananassa) cv. 'Hapil'. J. Hort. Sci. 70:705711. 